\title{
Interaction of Metallic Iron with Solutions Containing Humic Acids and $\mathrm{Cu}(\mathrm{II})$
}

\author{
Rima Binkienè $\dot{1}^{1}$ Ona Gyliené ${ }^{1}$, Romas Ragauskas ${ }^{1}$, Valentinas Gerasimovas ${ }^{2}$ \\ ${ }^{1}$ Center for Physical Sciences and Technology, Saulètekio av. 3, LT-10257 Vilnius, Lithuania \\ ${ }^{2}$ Vilnius Gediminas Technical University, Sauletekio al. 11, LT-10223 Vilnius, Lithuania
}

\begin{abstract}
Humic acids are responsible for the heavy metal movement in the environment. In order to diminish soil pollution with heavy metals the treatment of groundwater with metallic iron has been proposed. Investigations with model solutions containing humic acids and $\mathrm{Cu}(\mathrm{II})$ have shown that metallic iron is an effective decontaminant for humic acids containing solutions. The application of the mechanical brush-up of the passive layers from surface using rotating systems loaded with iron pieces gives satisfactory results. The decontamination rate depends mainly on solution $\mathrm{pH}$ and the iron surface renewal rate. The presence of $\mathrm{Cu}(\mathrm{II})$ ions in the solution or metallic copper in the load increase the decontamination rate.
\end{abstract}

Keywords-Humic acids; Copper ions, Metallic iron; Decontamination.

\section{INTRODUCTION}

The pollution of the environment with heavy metals is steadily increasing due to intensive agricultural and industrial activities. Among the anthropogenic pollutants, heavy metals make up a significant part. This pollution is caused mainly by atmospheric fallout from various sources, the most important being industrial and traffic emissions. Differently from organic pollutants, which may be destroyed to harmless substances, heavy metals are indestructible. Soil pollution by heavy metals has become a widespread serious problem in many parts of the world. Soils contaminated with heavy metals represent a permanent threat to soil ecosystems. Accumulated by plants heavy metals enter the food chain causing damage in animals and humans. However, the mobile species of heavy metals are most dangerous since dissolved in ground water they easily enter the living organisms [1,2]. The mobility of heavy metals is strongly influenced by the presence of other soil constituents and organic matter. The natural organic matter of soils is composed basically from humic substances. According to the solubility criteria, humic substances are divided into humic acids (which are not soluble in acidic solutions, but soluble at $\mathrm{pH}>2$ ), fulvic acids (which are soluble in water at all $\mathrm{pH}$ values) and humans (which are insoluble in water at any $\mathrm{pH}$ value). Humic acids and fulvic acids are two major components of humic substances. These acids are organic polyelectrolytes containing various functional groups such as carboxylic, phenolic, and hydroxyl groups, and some functional groups containing nitrogen, sulfur, and phosphorus which form strong complexes with heavy metals [36].Humic and fulvic acids, being soluble and capable of forming strong complexes, are responsible for heavy metal spreading in soils.

The implementation of effective techniques and processes for the treatment of contaminated wastewater and groundwater in order to remove or minimize the concentration of pollutants is essential for the environment protection and human health. Widely used methods for effluent treatment such as precipitation, coprecipitation, coagulation, electrocoagulation, sorption etc are ineffective in the case of polluted groundwater due to high stability of heavy metal complexes with humic substances and high stability of the latter $[7,8]$. Among the number of methods proposed for the treatment of the wastewaters of complicated chemical composition, zerovalentiron ( $\mathrm{Fe} 0)$ appears to be one of the most relevant [9-12]. Decontamination systems using zerovalent iron have a number of advantages: they are compact, cost effective; compatible with environment; the formed precipitate could be easily immobilized in building materials (concrete, bricks, expanded clays, etc.).

The iron dissolution proceeds with formation of $\mathrm{Fe}^{2+}$ or $\mathrm{Fe}^{3+}$. The latter gives an anamorphous precipitate. It is well known that this precipitate acts as a good sorbent for organic and inorganic substances. Due to the formation of iron hydroxides during decontamination the co-precipitation of contaminants with iron oxides also plays an important role. The possible mechanisms of aqueous contaminant removal by metallic iron materials are thoroughly discussed in [12-15]

The main reason for the limited use of iron for the decontamination of polluted groundwater and wastewaters in practice is the passivation of iron surface during the treatment process. To keep the surface active, different means have been proposed, i.e. the usage of salts and complexing agents, contact with more 
electronegative metals. In recent years, the main focus has been devoted to the production of nanoscale iron particles, which enhance the speed and efficiency of the pollutant removal in comparison with micro-scale metallic iron $[16,17]$. Usually they are synthesized in non-aqueous solvents using a catalyst and borohydride as a reducing agent. The synthesis and activity maintenance of zerovalent iron nanoparticles is expensive, the practical application is complicated.

This study deals with the mechanical brush-up of the iron surface with the purpose to keep them active during the decontamination process of humic acids containing solutions.

\section{EXPERIMENTAL}

\subsection{Decontamination experiments}

For the experiments model solutions containing humic acids and chemically pure copper sulphate were used. Solution $\mathrm{pH}$ was adjusted with diluted $(1: 10) \mathrm{H}_{2} \mathrm{SO}_{4}$ or 5 $\% \mathrm{NaOH}$ solutions. Decontamination was performed in the rotating systems loaded with metallic carbon steel or in the mixture with copper cylinders of $1 \mathrm{~cm}$ in diameter and length each (surface area of $4.71 \mathrm{~cm}^{2}$ ). These pieces were loaded in a rotating barrel and poured with $1 \mathrm{~L}$ of solutions containing humic acids or their mixture with copper sulfate.

\subsection{Analysis of solutions}

The concentration of humic acids was determined as COD (chemical oxygen demand) in the oxidation reaction with $\mathrm{K}_{2} \mathrm{Cr}_{2} \mathrm{O}_{7}$ after removal of $\mathrm{Fe}$ ions from the solution. In order to oxidize $\mathrm{Fe}$ (II) to $\mathrm{Fe}$ (III) the aliquot of solution after addition of alkali was kept in an open flask for 1 day and mixed occasionally. The Fe(III) hydroxides formed were removed using filtering through glass filters.

Total amounts of $\mathrm{Fe}(\mathrm{II})$ and $\mathrm{Fe}(\mathrm{III})$ in solutions were determined after $\mathrm{Fe}(\mathrm{III})$ reduction to $\mathrm{Fe}(\mathrm{II})$ with hydroxylamine; $\mathrm{Fe}(\mathrm{II})$ in solutions was determined photometrically at $\lambda=490 \mathrm{~nm}$ using o-nitrophenantroline as an indicator.

The concentration of $\mathrm{Cu}(\mathrm{II})$ in solutions was determined photometrically at $\lambda=440 \mathrm{~nm}$ using the indicator diethyldithiocarbamate after removal of iron ions with ammonium hydroxide. The formed precipitate, presumably consisting of $\mathrm{Fe}(\mathrm{II})$ and $\mathrm{Fe}(\mathrm{III})$ hydroxides, was removed using filtering through glass filters.

UV-visible spectra were recorded with a Perkin Elmar Lambda $35 \mathrm{UV} / \mathrm{VIS}$ spectrometer at $20^{\circ} \mathrm{C}$ in $1 \mathrm{~cm}$ length quartz cells.

\subsection{Analysis of the precipitate}

The precipitate was also examined by means of the dual beam system Helios NanoLab 650 (FEI) in secondary electrons mode at $500 \mathrm{eV}$ electron landing energy. EDS spectra were obtained on the same equipment using an Xmax $20 \mathrm{~mm}^{2}$ (Oxford Instruments) X-ray detector at 20 $\mathrm{kV}$.

\section{RESULTS AND DISCUSSION}

\section{A. Decontamination of solution}

Investigations showed that without renewal of iron surface the removal of $\mathrm{Cu}$ (II) from solutions stops after $\sim 0.5 \mathrm{~h}$ and that of humic acids after $\leq 1 \mathrm{~h}$. In order to find out the rotating rates for the most complete removal of passive layers from iron surface the experiments with different rotating rates during $1 \mathrm{~h}$ were carried out. Data depicted in Fig. 1 indicate that with increase of rotating rate the degree of both $\mathrm{Cu}(\mathrm{II})$ and humic acids increases and reaches its maximal values at 10 and 15 revolutions per minute (rpm) respectively. Further investigations were carried out at 2 different rotating rates, i.e. at 2 and $20 \mathrm{rpm}$ when iron dissolution is insufficient and when the iron dissolution rate at the least affects the decontamination process resprctively.

It is well known that the humic acids form strong complexes with heavy metals including $\mathrm{Fe}(\mathrm{II})$ and $\mathrm{Fe}$ (III) [3-6]. Their solubility depends on the ratio between the concentrations of humic acids and metal ions and $\mathrm{pH}$. Preliminary investigations using metallic iron for the humic acid removal from solution have shown that at the initial stage the dissolved iron makes soluble compounds. Later with an increase in dissolved iron concentration an insoluble precipitate forms. The effectiveness of the removal of humic acids from solutions can be easily evaluated visibly by its changes in color from brown to colorless. Humic acids demonstrate especially high absorbance in the UV wave-rang. Later with increase in wavelength it decreases (Fig. 2). Remarkably, the maximal absorbance is observed after some time, susceptibly, when the maximal amount of soluble iron-humic acid complex is formed. However, the COD (chemical oxygen demand), which reflects the humic acid concentration in the solution, steadily decreases.

Further investigations were focused mainly on the influence of $\mathrm{pH}$ and iron surface renewal rate (rotating rate) on the decontamination process. The enhancing effect of $\mathrm{pH}$ on the solubility of humic substances and hence on their mobility in soils is well known. On the other hand, increasing $\mathrm{pH}$ markedly slows down iron dissolution. However, the iron dissolution in the presence of humic substances is poorly investigated especially in the case when the iron surface is renewed mechanically. The data presented in Fig.3 showed a significant influence of both $\mathrm{pH}$ and rotating rate on the decontamination process. As it could be expected an increase in $\mathrm{pH}$ decreases the rate of both metallic iron 
dissolution and its reaction with solution constituents; meanwhile an increase in rotating rate enhances the removal of the inactive iron compound from the surface and the increase in available sites for the reaction of solution components. In this case the decontamination rate remarkably increases.

Similar effects of $\mathrm{pH}$ and rotating rate are seen in the case when $\mathrm{Cu}$ (II) ions are present in the solution (Fig. 4). However, in this case the humic acid removal rate remarkably increases and the concentrations of $\mathrm{Fe}$ ions in solution become considerably lower. Besides, $\mathrm{Cu}$ (II) ions from the solution are completely removed after $0.5 \mathrm{~h}$ of treatment. Such an enhancing effect of $\mathrm{Cu}$ (II) ions on the decontamination process could be explained by either binding a part of humic acids with $\mathrm{Cu}$ (II) ions or an increase in metallic iron dissolution rate due to the formation of a galvanic pair of reduced copper on the iron surface. The recorded UV/Vis spectra also demonstrate a dramatic increase in absorbance in solutions containing $\mathrm{Cu}$ (II) indicating the formation of strong bonds between the humic acids and $\mathrm{Cu}(\mathrm{II})$.

In order to check the influence of $\mathrm{Fe}-\mathrm{Cu}$ galvanic pair on the decontamination process the experiments were carried out with a load composed of iron and $\mathrm{Cu}$ pieces. The results of the investigations are presented in Fig 5 and Table 1. The humic acids removal rate is higher than that in the case of a simple Fe load and lower than that when $\mathrm{Cu}(\mathrm{II})$ is added into the solution. The content of $\mathrm{Fe}$ ions in this case is also lower than that in the case of Fe load and higher than that in the case of the addition of $\mathrm{Cu}$ (II) to the solution.

A strong effect of $\mathrm{Cu}(\mathrm{II})$ on the decontamination process is also seen in the case when $\mathrm{Cu}$ (II) is added to the solution in the form of a strong complex such as EDTA (Fig.6). The decontamination of the solution containing $\mathrm{Cu}$ (II)-EDTA complexes is a hard-to-solve problem. The application of metallic iron at optimal $\mathrm{pH} \sim 3$ enables to achieve a rather high degree of the removal of this complex. However, in alkaline solutions the effectiveness of decontamination is low.

Despite the uncomplimentary assessment of the kinetic investigations [18], the kinetic peculiarities of humic acid removal were evaluated by testing the experimental data according to the first order (1) and second order (2) kinetic equations:

$$
\begin{aligned}
& c=c_{\mathrm{O}} \cdot e^{-k_{1} t} \\
& \frac{1}{c}-\frac{1}{c_{0}}=k_{2} t
\end{aligned}
$$

where $c$ is the concentration of humic acid at time $t, \mathrm{mg}$ $\mathrm{L}^{-1}, c_{o}$ is the initial concentration of humic acid $\mathrm{mg} \mathrm{L}^{-1}$; $k_{1}$ is the first order reaction rate constant, $\mathrm{h}^{-1}$, and $k_{2}$ is the second order reaction rate constant, $\mathrm{L} \mathrm{mg}^{-1} \square \mathrm{h}^{-1}$. The plotting $\ln c$ or $1 / c$ versus $t$ enables to determine $-k_{1}$ ork $k_{2}$, respectively.

In kinetic experiments a coincidence regarded as reasonably satisfactory was obtained applying the first order and the second order rate equations. The parameters are presented in Table 1 . The values of the regression coefficients $\mathrm{R}^{2}>0.9$ indicate the possible run of process according to the first and second order reaction models. The presented values of $k_{1}$ and $k_{2}$ indicate that the reaction between the humic acids and $\mathrm{Fe}$ most rapidly proceeds at $\mathrm{pH} 6$ and higher rotating rates, while it is slower at $\mathrm{pH} 8$ and lower rotating rates, except for the case depicted in Fig. 4, curve 3, when the highest $k_{1}$ and $k_{2}$ are obtained at $\mathrm{pH} 8$.

The estimated better fit of kinetic data to the first and second order equations points to a rather complicated mechanism of humic acids and their $\mathrm{Cu}$ (II) complex removal from the solution. Actually, thetheoretical aspects of the decontamination of hazardous substances using iron have not been thoroughly investigated yet and most likely they are more complicated than the complexation or precipitation of insoluble compounds. Firstly, not only iron but also the hydrogen evolved during iron dissolution can act as a reducingagent. The reductive destruction proceeds when iron is applied to decontaminate solutions containing hazardous compouds such as chlorinated solvents, dioxines, pesticides, dyes etc. Metallic iron easily destroys unsaturated bonds in many organic compounds. Being of complicated organic composition, humic acids also could undergo reductive destruction.

Depending on $\mathrm{pH}$ and th epresence of an oxidizing agent, for instant oxygen, the iron dissolution reaction proceeds with formation of $\mathrm{Fe}^{2+}$ or $\mathrm{Fe}^{3+}$. The dissolved iron undergoes further spontaneous reactions to produce hydroxides and/or polyhydroxides.

$$
\begin{aligned}
& 2 \mathrm{Fe}^{2+}+1 \square 2 \mathrm{O}_{2}+3 \mathrm{H}_{2} \mathrm{O} \square 2 \mathrm{FeOOH}+4 \mathrm{H}^{+}, \\
& 2 \mathrm{Fe}^{2+}+1 \square 2 \mathrm{O}_{2}+2 \mathrm{H}_{2} \mathrm{O} \square \mathrm{Fe}_{2} \mathrm{O}_{3}+4 \mathrm{H}^{+} .
\end{aligned}
$$

It is well known that this amorphous precipitate acts as a good sorbent for organic and inorganic substances. Due to the formation of iron hydroxides during the decontamination process, the coprecipitation of contaminants also plays an important role. The formation of polynuclear iron-hidroxococmplexes is also possible. These complexes distinguish themselves by high sorption capacity. The possible mechanisms of aqueous contaminant removal by metallic iron materials are thoroughly discussed in [15-18].

\section{B. Investigations of precipitate}

Differently from other precipitates, the distinctive feature of the precipitate formed using treatment with metallic 
iron is its compactness. The precipitate is magnetic and easily removable from solutions.

Sure enough, investigations of the chemical composition of precipitate (Table 2) have shown that it is composed from three main elements: consituents of humic acids, i.e. oxygen and carbon, and iron from steel. Precipitate also contains small amounts of impurities from carbon steel or humic acids such as $\mathrm{Mn}, \mathrm{Si}$, Ca. When the solutions contain $\mathrm{Cu}$ (II) ions (Fig. 4, Table 2) the content of $\mathrm{Cu}$ in the precipitate is also significant. However, the precipitate formed under different conditions also differs in composition. As a rule, the amount of carbon in the precipitate decreases with increase in the amount of Fe. This effect correlates with the effectiveness of decontamination. The most rapid and complete treatment of solutions containing humic acid sgives the precipitate containing a low amount of $\mathrm{Fe}$ and a high amount of carbon as it is in the case depicted in Fig.4, curve 1.

The morphology of the precipitate was observed by scanning electron microscopy (SEM) (Fig. 7). All the samples investigated have shown a typical grainy constitution characteristic of compact compounds.

IV. FIGURES AND TABLES

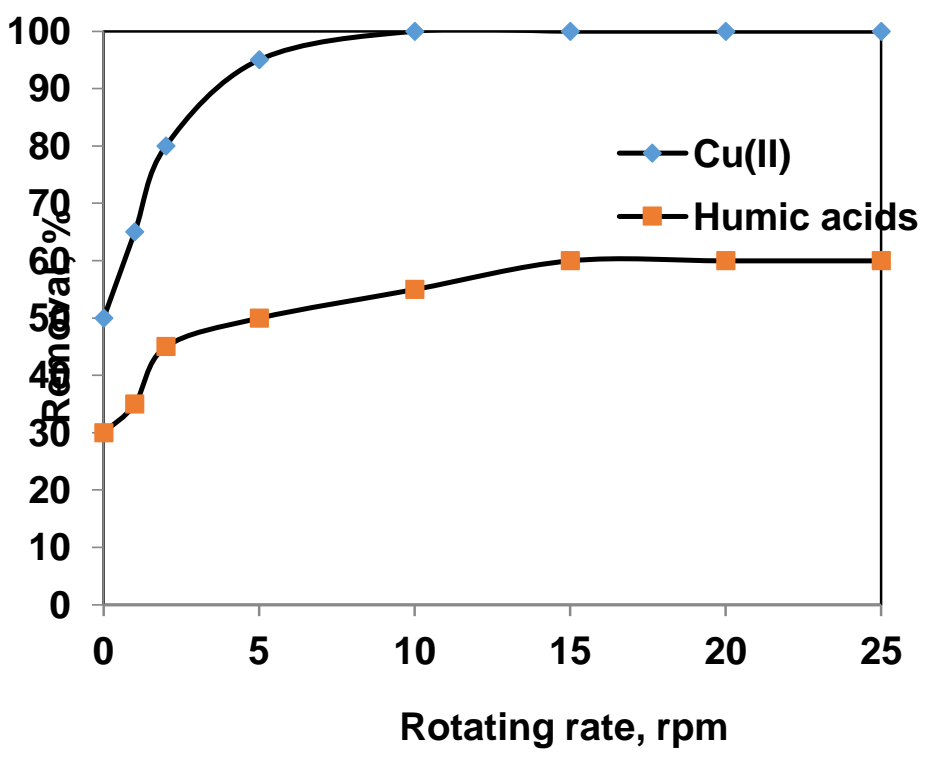

Fig. 1. Cu(II) and Humic acids removal from their $100 \mathrm{mg} \mathrm{L} \mathrm{L}^{-1}$ solutions. Load-100 Fe pieces of $4.71 \mathrm{~cm} 2 \mathrm{surface}$; initial $\mathrm{pH} 3$; rotating rate $20 \mathrm{rpm}$

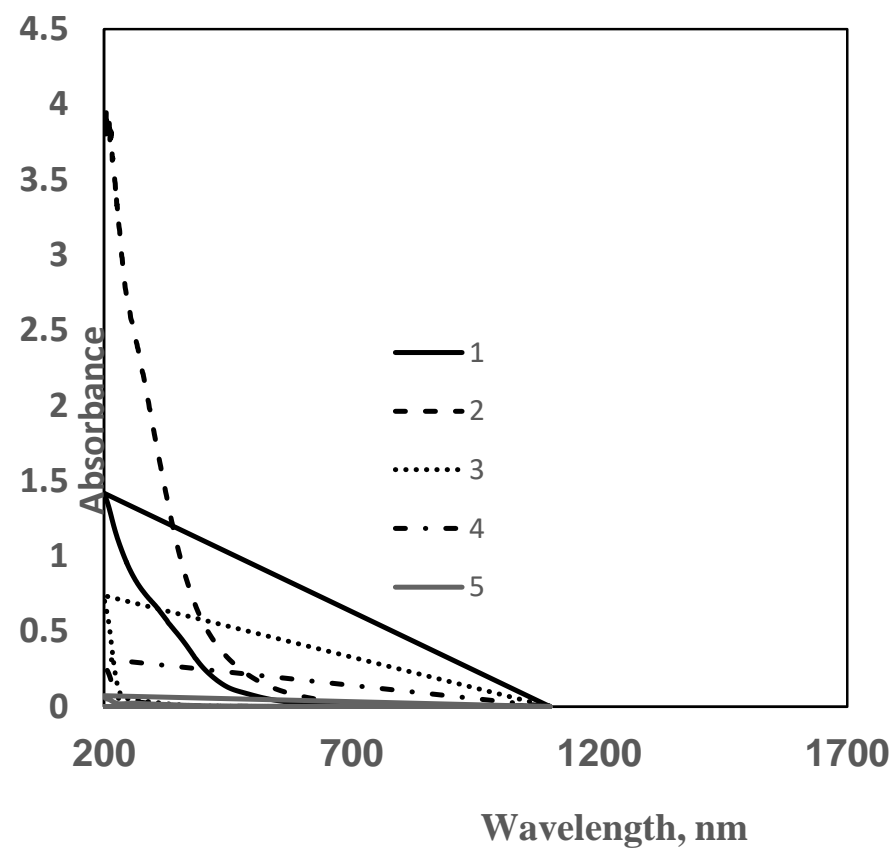

Fig.2: UV/vis spectra of $100 \mathrm{mg} \mathrm{L-1} \mathrm{humic} \mathrm{acids} \mathrm{containing} \mathrm{solution} \mathrm{in} \mathrm{dependence} \mathrm{on} \mathrm{treatment} \mathrm{time} \mathrm{with} \mathrm{metallic} \mathrm{iron} \mathrm{(h):}$ 1 - 0;2 - 1;3-4;5-6. Load-100 Fe pieces of $4.71 \mathrm{~cm} 2$ surface; initial pH 3; rotating rate $20 \mathrm{rpm}$ 


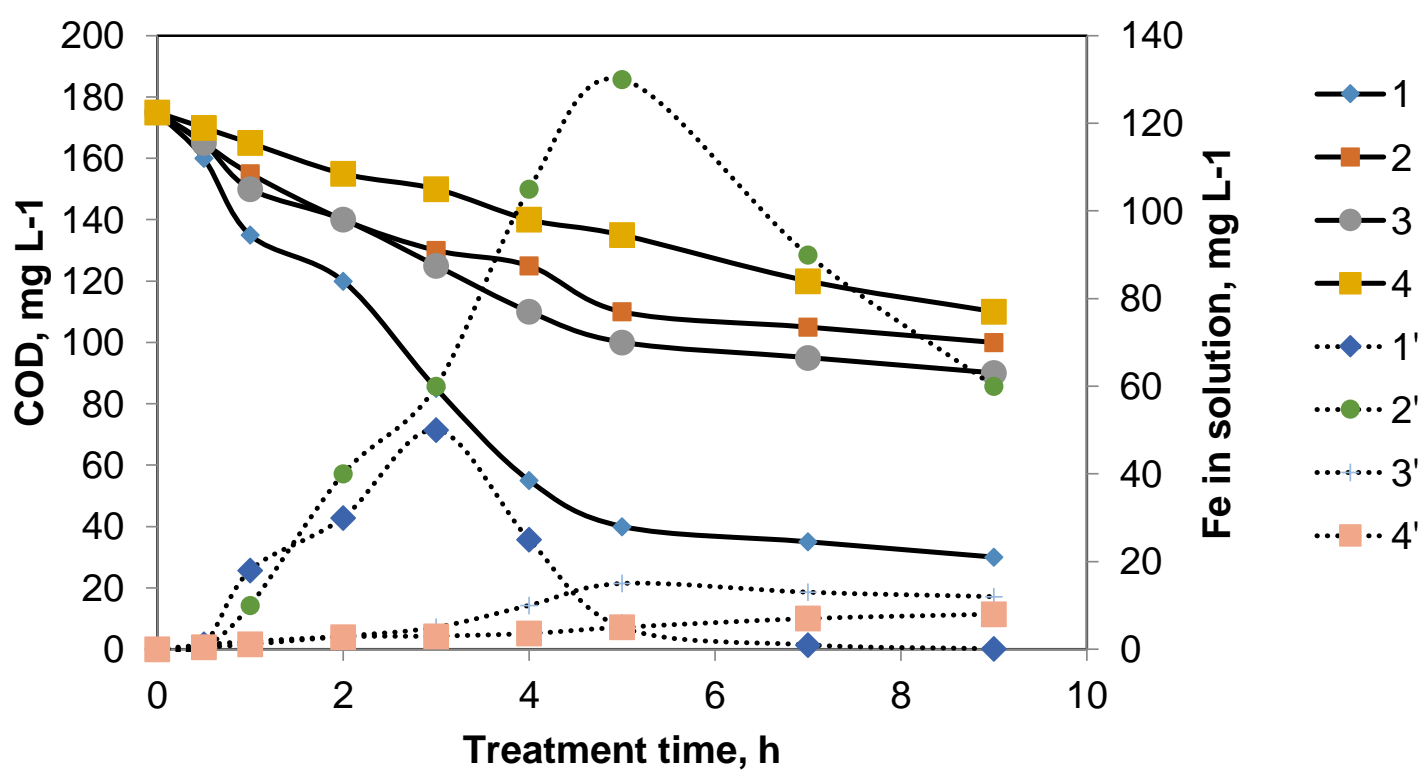

Fig.3. Humic acids as $C O D$ (1, 2, 3 and 4) and Fe total (1', 2', 3' and 4') concentration changes with treatment time in solution containing initially $100 \mathrm{mg} \mathrm{L-1} \mathrm{humic} \mathrm{acids.} \mathrm{Load-100} \mathrm{Fe} \mathrm{pieces} \mathrm{of} 4.71 \mathrm{~cm}^{2}$ surface; initial pH 6 (1, 1', 2 and 2') and 8 (3, 3', 4 and 4'); rotating rate $20 \mathrm{rpm}$ (1, 1', 3 and 3') and $2 \mathrm{rpm}$ (2, 2', 4 and')

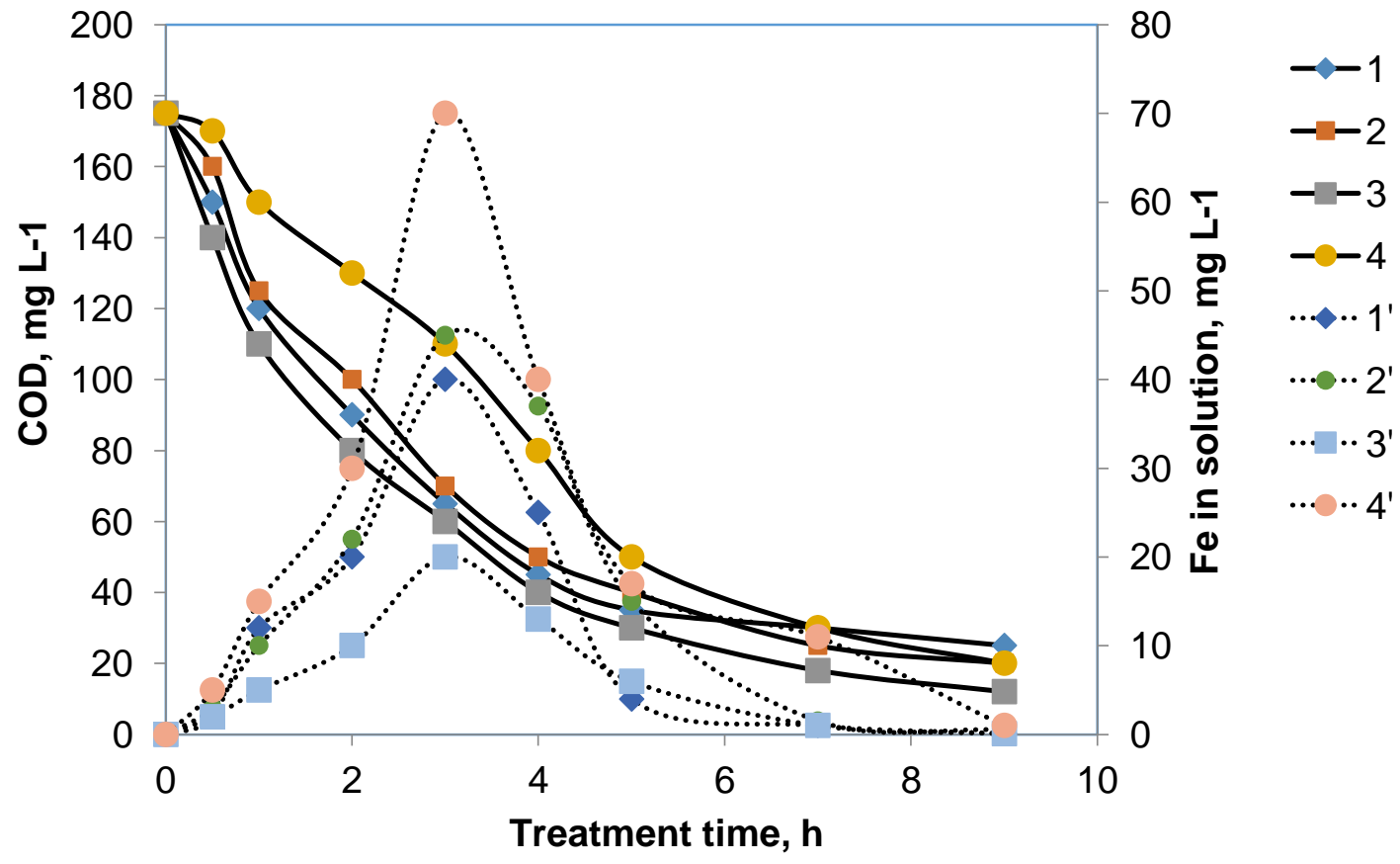

Fig.4. Humic acids as $C O D$ (1, 2, 3 and 4) and Fe total (1', 2', 3' and 4') concentration changes with treatment time in solution containing initially $100 \mathrm{mg} \mathrm{L}^{-1}$ humic acids and $64 \mathrm{mg} \mathrm{L}^{-1} \mathrm{Cu}(\mathrm{II})$. Load-100 Fe pieces of $4.71 \mathrm{~cm}^{2}$ surface; initial pH 6 (1, 1', 2 and 2') and 8 (3, 3', 4 and 4'); rotating rate $20 \mathrm{rpm}$ (1, 1', 3 and 3') and $2 \mathrm{rpm}$ (2, 2', 4 and 4') 


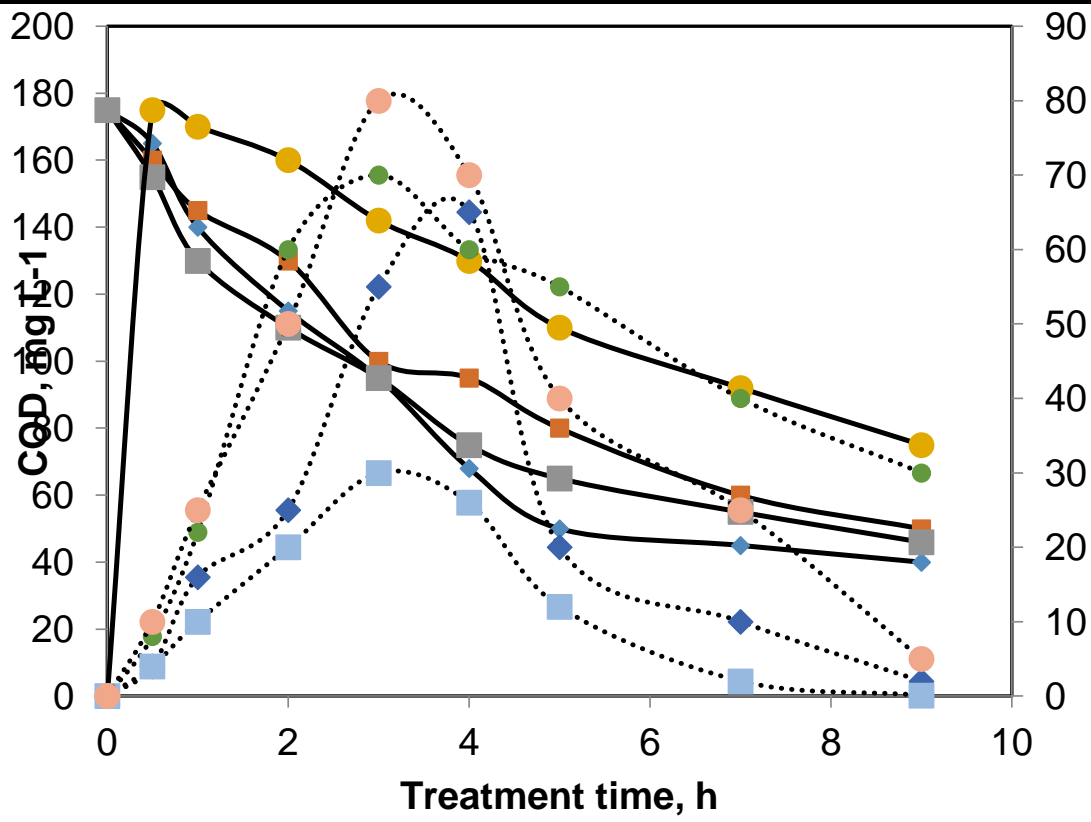

90

80

70

60

50

40

30

20

10

0

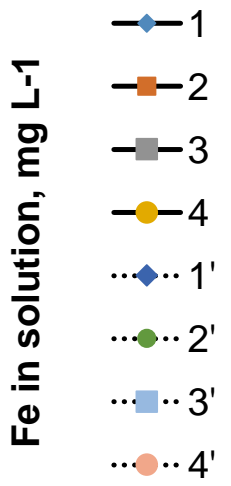

Fig. 5. Humic acids as $C O D$ (1,2, 3 and 4) and Fe $e_{\text {total }}$ (1', 2', 3' and 4') concentration changes with treatment time in solution containing initially $100 \mathrm{mg} \mathrm{L}^{-1}$ humic acids. Load-100 Fe pieces of $4.71 \mathrm{~cm} 2$ surface and $50 \mathrm{Cu}$ pieces $4.71 \mathrm{~cm}^{2}$ surface ; initial pH 6 (1, 1', 2 and 2') and 8 (3, 3', 4 and 4'); rotating rate $20 \mathrm{rpm}$ (1, 1', 3 and 3') and 2 rpm (2, 2', 4 and 4')

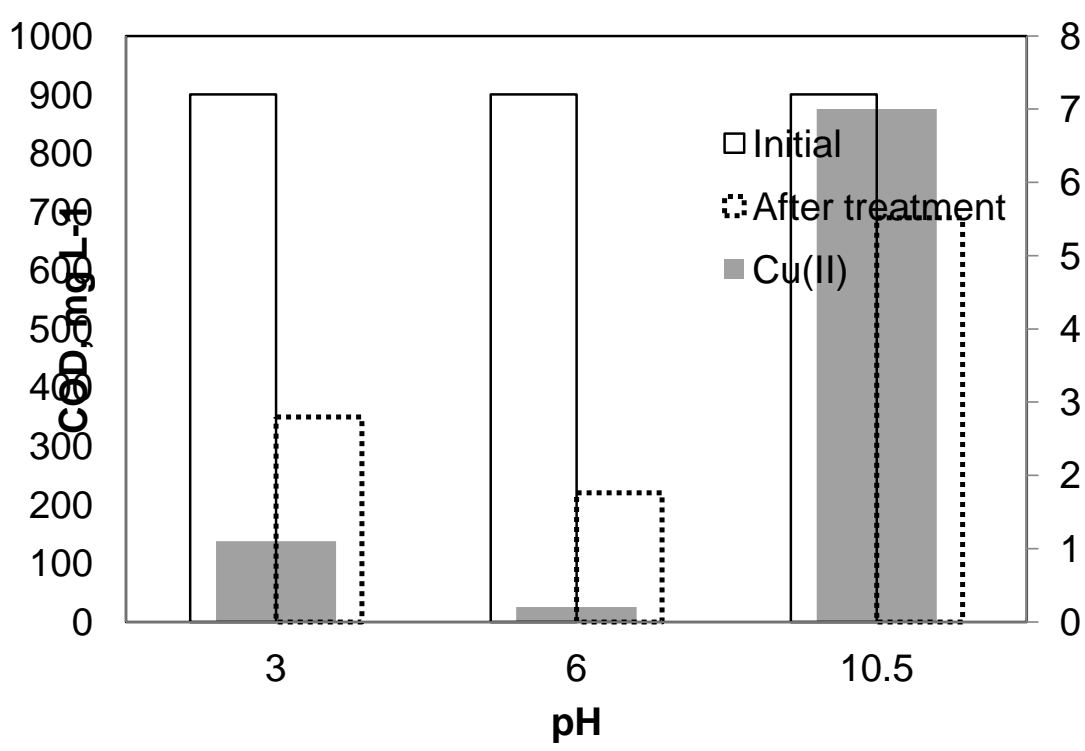

Fig. 6. Influence of pH on organic matter and Cu(II) removal from solutions containing humic acids $200 \mathrm{mg} \mathrm{L}^{-1}$, EDTA - $2 \mathrm{mmol} \mathrm{L}^{-1}$ and $\mathrm{Cu}(\mathrm{II})-1 \mathrm{mmol} \mathrm{L^{-1 }}$. Load-100 Fe pieces of $4.71 \mathrm{~cm}^{2}$ surface; rotating rate $20 \mathrm{rpm}$ 


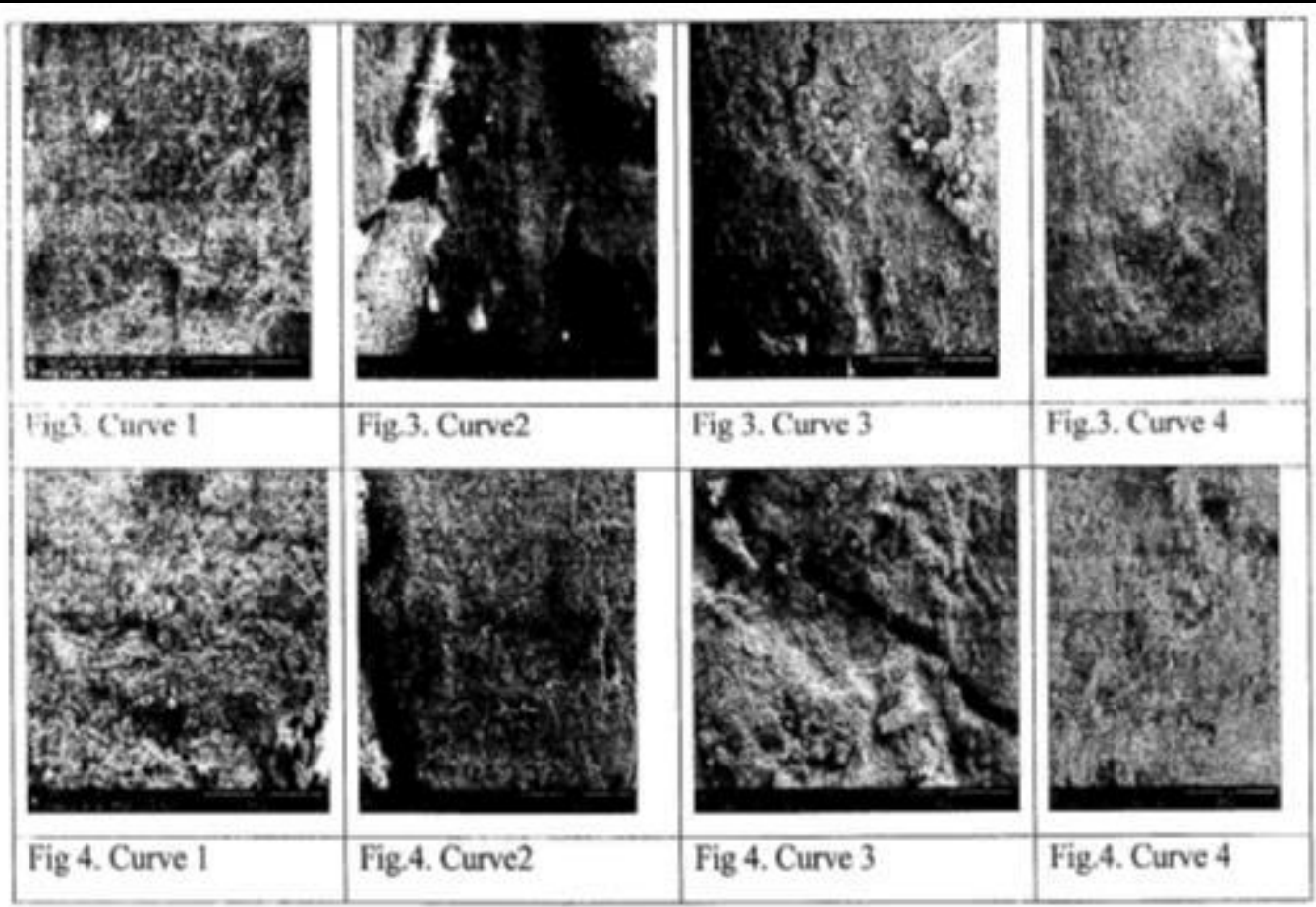

Fig, 7: SEM images of precipitate. Experiment conditions confirm those given in captions to Figures

$\bullet$

Table.1: The first and second order rate constants and correlation coefficients in kinetic experiments

\begin{tabular}{|l|l|l|l|l|}
\hline \multirow{2}{*}{$\begin{array}{l}\text { Treatment conditions } \\
\text { as in }\end{array}$} & \multicolumn{2}{|l|}{ First order reaction parameters } & \multicolumn{2}{l|}{ Second order reaction parameters } \\
\cline { 2 - 5 } & $k_{l}, \mathrm{~h}^{-1}$ & $\mathrm{R}^{2}$ & $k_{2},{\mathrm{~L} \mathrm{~m}^{-1} \square \mathrm{h}^{-1}}^{2}$ & $\mathrm{R}^{2}$ \\
\hline Fig.3 Curve 1 & 0.256 & 0.96 & 0.001 & 0.959 \\
\hline Curve 2 & 0.63 & 0.934 & 0.003 & 0.962 \\
\hline Curve3 & 0.77 & 0.924 & 0.001 & 0.952 \\
\hline Curve4 & 0.051 & 0.997 & 0.001 & 0.996 \\
\hline Fig.4 Curve 1 & 0.227 & 0.927 & 0.004 & 0.982 \\
\hline Curve 2 & 0.255 & 0.977 & 0.005 & 0.973 \\
\hline Curve 3 & 0.3 & 0.982 & 0.008 & 0.941 \\
\hline Curve4 & 0.256 & 0.986 & 0.004 & 0.901 \\
\hline Fig.5 & 0.18 & 0.988 & 0.002 & 0.963 \\
\hline Curve 2 & 0.142 & 0.958 & 0.001 & 0.986 \\
\hline Curve 3 & 0.149 & 0.94 & 0.001 & 0.995 \\
\hline Curve 4 & 0.123 & 0.001 & 0.975 \\
\hline
\end{tabular}

Table.2: Chemical composition of precipitates

\begin{tabular}{|l|l|l|l|l|l|l|l|l|l|l|}
\hline \multirow{2}{*}{$\begin{array}{l}\text { Treatment } \\
\text { conditions }\end{array}$} & \multicolumn{6}{|l|}{ Content of elements in atomic $\%$} & Remarks \\
\cline { 2 - 10 } & $\mathrm{C}$ & $\mathrm{O}$ & $\mathrm{Na}$ & $\mathrm{Si}$ & $\mathrm{S}$ & $\mathrm{Ca}$ & $\mathrm{Mn}$ & $\mathrm{Fe}$ & $\mathrm{Cu}$ & \\
\hline $\begin{array}{l}\text { Fig3. Curve } \\
1\end{array}$ & 35,39 & 46,33 & 0,27 & 0,14 & 0,14 & 0,05 & 0,1 & 17,56 & 0,01 & Nonmagnetic \\
\hline $\begin{array}{l}\text { Fig3. Curve } \\
2\end{array}$ & 31,18 & 49,01 & 0,31 & 0,15 & 0,13 & 0,04 & 0,1 & 19,05 & 0,03 & Nonmagnetic \\
\hline $\begin{array}{l}\text { Fig3. Curve } \\
3\end{array}$ & 36,76 & 45,55 & 0,47 & 0,19 & 0,18 & 0,08 & 0,11 & 16,68 & 0 & Magnetic \\
\hline $\begin{array}{l}\text { Fig3. Curve } \\
4\end{array}$ & 40,99 & 42,73 & 0,3 & 0,23 & 0,14 & 0,07 & 0,07 & 15,37 & 0,1 & Magnetic \\
\hline $\begin{array}{l}\text { Fig. 4 } \\
\text { Curve } 1\end{array}$ & 40,88 & 42,89 & $-0,02$ & 0,13 & 0,15 & 0,03 & 0,07 & 12,91 & 2,96 & Magnetic \\
\hline Fig. 4 & 38,5 & 43,98 & 0 & 0,11 & 0,6 & 0,01 & 0,02 & 14,28 & 2,49 & Magnetic \\
\hline
\end{tabular}




\begin{tabular}{|l|l|l|l|l|l|l|l|l|l|l|}
\hline Curve 2 & & & & & & & & & & \\
\hline $\begin{array}{l}\text { Fig. 4 } \\
\text { Curve 3 }\end{array}$ & 37,37 & 44,37 & 0,01 & 0,17 & 0,15 & 0,05 & 0,08 & 14,7 & 3,09 & Magnetic \\
\hline $\begin{array}{l}\text { Fig. 4 } \\
\text { Curve 4 }\end{array}$ & 41,5 & 41,66 & 0,03 & 0,23 & 0,19 & 0,06 & 0,06 & 12,49 & 3,82 & Magnetic \\
\hline $\begin{array}{l}\text { Fig. 5 } \\
\text { Curve 1 }\end{array}$ & 43 & 41,44 & 0,09 & 0,13 & 0,07 & 0,05 & 0,08 & 14,94 & 0,19 & Magnetic \\
\hline $\begin{array}{l}\text { Fig. 5 } \\
\text { Curve 2 }\end{array}$ & 38,39 & 44,32 & 0,11 & 0,14 & 0,08 & 0,05 & 0,1 & 16,63 & 0,17 & Magnetic \\
\hline
\end{tabular}

\section{CONCLUSION}

Metallic iron is an effective decontaminant for solutions containing humic acids. The application of mechanical brush-up of the passive layers from the surface using rotating systems loaded with iron pieces gives satisfactory results.

The decontamination rate depends mainly on solution $\mathrm{pH}$ and the iron surface renewal rate.

The presence of both $\mathrm{Cu}(\mathrm{II})$ ions in the solution or metallic copper in the load increases the decontamination rate.

\section{REFERENCES}

[1] J. Kumpiene, G.Guerri, L.Landi, G.Pietramellara, P.Nannipieri, G.Renella, Microbial biomass, respiration and enzyme activities after in situaided phytostabilization of a $\mathrm{Pb}$-and $\mathrm{Cu}$-contaminated soil. Ecotoxicology and Environmental Safety 72 (2009) 115-119.

[2] R. BouKheir, B. Shomar, M.B. Greve, M.H. Greve, On the quantitative relationships between environmental parameters and heavy metals pollution in Mediterranean soils using GIS regression-trees: The case study of Lebanon. Environmental Pollution 206 (2015) 227-235.

[3] J. Burlakovs, M. Klavins, L. Osinska, O. Purmalis, The Impact of Humic Substances as Remediation Agents to the Speciation Forms of Metals in Soil. APCBEE Procedia 5 ( 2013 ) 192 - 196.

[4] Wang-Wang Tang, Guang-Ming Zeng, Ji-Lai Gong, Jie Liang, Piao Xu, Chang Zhang, Bin-Bin Huang, Impact of humic/fulvic acid on the removal of heavy metals from aqueous solutions using nanomaterials: A review, Science of the Total Environment 468-469 (2014) 1014-1027.

[5] Medhat A. Shaker, Hassan M. Albishri, Dynamics and thermodynamics of toxic metals adsorption onto soil-extracted humic acid, Chemosphere 111 (2014) 587-595.

[6] Qi Wang, ZhiyiXie, Fangbai Li, Using ensemble models to identify and apportion heavy metal pollution sources in agricultural soils on a local scale, Environmental Pollution 206 (2015) 227-235.
[7] Kai Fang, Dongxing Yuan, Lei Zhang, Lifeng Feng, Yaojin Chen, Yuzhou Wang, Effect of environmental factors on the complexation of iron and humic acid, Journal of Environmental Sciences 27 (2015) 188196.

[8] C. Colombo, G. Palumbo, V. Michele Sellitto, H. Goo Cho, C. Amalfitano, P.a Adamo, Stability of coprecipitated natural humic acid and ferrous iron under oxidative conditions, Journal of Geochemical Exploration 151 (2015) 50-56.

[9] Y. Han, W. Yan, Bimetallic nickel-iron nanoparticles for groundwater decontamination: Effect of groundwater constituents on surface deactivation. Water Res. 66 (2014) 149-159.

[10] J. Kumpiene, S. Ore, G. Renella, M. Mench, A. Lagerkvist, Ch. Maurice, Assessment of zerovalent iron for stabilization of chromium, copper, and arsenic in soil, Environmental Pollution 144 (2006) 62-69

[11] J. Kumpiene, I. Castillo Montesinos, A. Lagerkvist, Ch. Maurice, Evaluation of the critical factors controlling stability of chromium, copper, arsenic and zinc in iron-treated soil, Chemosphere 67 (2007) $410-417$

[12] O. Gyliene, T. Vengris, O. Nivinskiene, R. Binkiene, Decontamination of solutions containing $\mathrm{Cu}(\mathrm{II})$ and ligands tartrate, glycine and quadrol using metallic iron. J. Hazard. Mater. 175 (2010) 452-459.

[13]C. Noubactep, 'A critical review on the process of contaminant removal in $\mathrm{Fe} 0-\mathrm{H} 2 \mathrm{O}$ systems', Environ. Technol., , 29(2008) 909-920.

[14]R. Rangsivek, M.R. Jekel, 'Removal of dissolved metals by zero-valent iron (ZVI):Kinetics, equilibria, processes and implications for stormwater runoff treatment, Water Res.39 (2005) 4153-4163.

[15]D. Karabelli, C. Uzum, T. Shahwan, A. E. Eroglu, T. B. Scott, K. R. Hallam, I. Lieberwirth, Batch Removal of Aqueous Cu2+ Ions Using Nanoparticles of Zero-Valent Iron: A Study of the Capacity and Mechanism of Uptake, ,Ind. Eng. Chem. Res. 47 (2008) 4758-4764.

[16] Tingyi Liu, Zhong-Liang Wang, Yanqiu Sun. Manipulating the morphology of nanoscale zero- 
valent iron on pumice for removal of heavy metals from wastewater, Chemical Engineering Journal 263 (2015) 55-61

[17] Seol Ah Kim, Seralathan Kamala-Kannan, Kui-Jae Lee, Yool-Jin Park, Patrick J. Shea,Wang-Hyu Lee, Hyung-Moo Kim, Byung-Taek Oha, Removal of $\mathrm{Pb}$ (II) from aqueous solution by a zeolitenanoscalezero-valent iron composite. Chemical Engineering Journal 217 (2013) 54-60.

[18]C. Noubactep, On the validity of specific rate constants (kSA) in $\mathrm{Fe} 0 / \mathrm{H} 2 \mathrm{O}$ systems', J. Hazard. Mater. 164 (2009) 835-837. 